\title{
Numerical test on polystyrene tunnel seismic-isolation material
}

\author{
Jianping $\mathrm{He}^{1^{*}}$, Weizhong $\mathrm{Chen}^{2}$, Wusheng Zhao ${ }^{2}$, Sheng Huang ${ }^{3}$, Yunlong Yao ${ }^{1}$ \\ ${ }^{1}$ Shandong University at Weihai, Weihai 264209, China \\ ${ }^{2}$ Chinese Academy of Sciences, State Key Laboratory of Geomechanics and Geotechnical Engineering, Institute of Rock \\ and Soil Mechanics, Wuhan 430071, China \\ ${ }^{3}$ China Railway Siyuan Survey and Design Group Co., Ltd., Wuhan 430063, China \\ "Corresponding author: e-mail: hejianping@sdu.edu.cn
}

\begin{abstract}
Stress-strain mechanical properties of polystyrene foam plastic material were tested under different loading conditions. An empirical constitutive model for describing metal materials was proposed for the polystyrene plastic foam. The static and dynamic tests results show that the ductility and watertightness of the polystyrene plastic foam are significantly improved. At the same time, in order to check its seismic-isolation property, the high-performance foam concrete as filling materials of Galongla tunnel in Tibet was simulated by FEM. The simulated results show that the polystyrene plastic foam can remarkably decrease the stress and the plastic zone in final lining, so it can effectively reduce the seismic damage of the tunnel. Considering the seismic-isolation property and low price of polystyrene plastic foam, it is a good reference for the anti-seismic design of tunnels in high intensity zones.
\end{abstract}

Keywords: polystyrene plastic foam; constitutive model; high intensity; tunnel; seismic-isolation layer.

\section{INTRODUCTION}

The tunnel structure to pass through the seismic zone is inevitable. The seismic research of tunnels has been made a great progress. Experimental research on seismic materials has been in constant innovation and development stage' ${ }^{1}$ A 'rock-primary support-buffer layer-the second lining' mode is put forward by $\mathrm{Xu} \mathrm{Hua}{ }^{2}$. Geng Ping carried out a physical model test of vibration table for setting up the damping layer ${ }^{3}$. Wang Mingnian established a damping model of setting shock absorption layer in the supporting system of tunnel ${ }^{4}$. Chen Liang studied longitudinal seismic response and effect of aseismatic joint of tunnel entrance in fault zone ${ }^{5}$.

The polystyrene foam has the advantages of low density, high specific modulus, high specific strength, also has good energy absorption performance for vibration and impact, which plays a very important role in product protection packaging. In this paper, the polystyrene plastic foam materials are applied to the seismic design of tunnel. Using test data to describe the vibration isolation and cushioning properties of polystyrene plastic foam, the mechanical constitutive model of plastic foam is established. Through the simulation experiment, the seismic effect of the polystyrene tunnel resistant layer is evaluated. The results of numerical calculation show that the damping effect of the polystyrene as tunnel isolation material is good. The research provides a reference for the research of the tunnel isolation layer and the seismic design of the high seismic intensity region, and made a very important test basis for finding the ideal tunnel seismic material.

\section{MATERIAL PERFORMANCE TESTING AND ANALYSIS}

Polystyrene (EPS) foam is a kind of low density and porous cushioning material, which has experienced three stages, such as elastic deformation, yield platform and compression failure, under the condition of dynamic and static loading. Elastic deformation stage reflects the bearing and deformation characteristics of the foam skeleton structure, yield platform stage reflects the skeleton structure been crushed and buckling characteristics, compression failure stage mainly reflects the characteristics of the skeleton and matrix.

Because the foam material has a yield stress of a long platform, it is particularly suitable for cushion packaging product. For example, in the stress platform section, the bubble hole inside material is gradually destroyed, and the energy is absorbed in the constant stress approximation. Therefore, the more energy it can absorb on the maximum allowable stress, the better the effect of vibration isolation buffer.

Using polystyrene foam as the specimen, the specimen density is $18.3 \mathrm{~kg} / \mathrm{m}^{3}$. Specimens were cut into square block, the width of the specimen being $100 \mathrm{~mm}$, the length being $100 \mathrm{~mm}$, and the thickness being $48 \mathrm{~mm}, 40 \mathrm{~mm}$ and $28 \mathrm{~mm}$, respectively, and 9 specimens show different thicknesses. The experiment was carried out at $20^{\circ} \mathrm{C}$ with a relative humidity of $75 \%$ and the compression speed of $12 \mathrm{~mm} / \mathrm{min}$. By using the WDW-20E microcomputer control electronic universal testing machine using the static compression test method of cushioning materials for packaging (GB8168-87), the stress-strain relationship of polystyrene plastic foam was measured ${ }^{\mathbf{6}}$.

The average stress-strain curves of the three specimens with different thicknesses are shown in Figure 1. The physical and chemical properties of polystyrene foam plastic are shown in Table 1 . The polystyrene was produced by Jiangsu Wuxi Xingda foam New Materials Co., Ltd, China.

The experimental results show that the uniaxial compression process of polystyrene foamed plastics has obvious elastic deformation section (strain $0 \sim 0.06$ ),

Table 1. The physical and chemical properties of polystyrene foam plastic

\begin{tabular}{|l|c|c|c|c|c|}
\hline Density $\left[\mathrm{kg} \cdot \mathrm{m}^{-3}\right]$ & Relative molecular mass & $\begin{array}{c}\text { Elastic modulus } \\
{[\mathrm{KPa}]}\end{array}$ & Poisson ratio & Compressive strength [KPa] & $\begin{array}{c}\text { Tensile strength } \\
{[\mathrm{KPa}]}\end{array}$ \\
\hline 18.3 & 110300 & 1120 & 0.45 & 105 & 197 \\
\hline
\end{tabular}




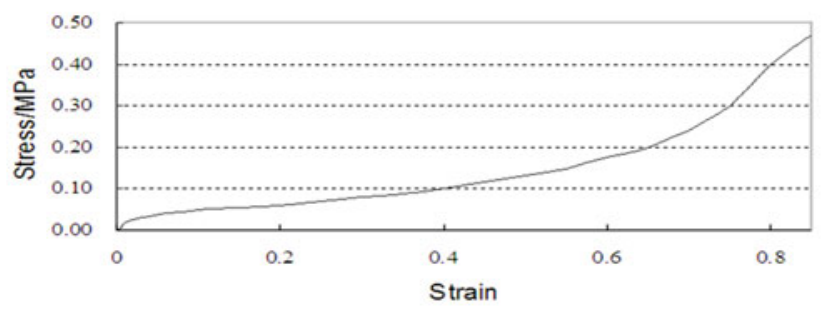

Figure 1. Experimental stress-strain curves of polystyrene foam plastic

the yield platform section (about $0.06 \sim 0.56$ ) and the compression failure stage $(0.6 \sim 1)$, and the distribution of the three stages is obvious. Material in the case of small strain showed a good elasticity, with the increase of the load the material produced a large elastic plastic deformation, the corresponding curve presented a long smooth stage, with the increase of the strain the material structure was destroyed, the stress of transfer will rise sharply. The isolation vibration design pays attention to the elastic deformation of the material, and the buffer design pays attention to the material's yield platform.

\section{MODEL BUILDING AND PARAMETER IDENTIFI- CATION}

The analysis results showed that the density of polystyrene foam plastic had little effect, but the material thickness and deformation speed had a great influence on the properties of foam plastic. According to the basic characteristics of the material properties, based on Avalle theory the nonlinear constitutive model of foamed plastics is established:

$$
\sigma=R \cdot\left(1-e^{(-E / R) \cdot \cdot \cdot(1-\varepsilon)^{m}}\right)+B \cdot\left(\frac{\varepsilon}{1-\varepsilon}\right)^{n}
$$

In the formula, $R$ is the material yield stress, $E$ is the initial elastic modulus of materials, $B$ is the material enhancement coefficient, $\varepsilon$ is the material strain, and $m$ and $n$ are constant parameters. There are 6 parameters, and the trend of the model curve is independent of the material density.

According to the compression test data, the penalty function optimization method is adopted, fitted the test results of the foam plastic, identify the 2 common parameters of the nonlinear Avalle stress-strain model of the polystyrene foam plastic, through the analysis and adjustment of $\mathrm{M}$ and $\mathrm{N}$, we get the best value $\mathrm{m}=0.316$ and $\mathrm{n}=0.6411$.

\section{ENGINEERING EXAMPLES}

\section{Engineering survey}

Galongla tunnel is located at the junction area of Bomi county and Medog county in Tibet Linzhi area, is a new control engineering of Zamo highway engineering, crossing the Kangri mountains, tunnel length $3450 \mathrm{~m}$, the maximum depth of about $833 \mathrm{~m}$. The photo of Galongla tunnel is shown in Figure 2. In the near field, there are NW and NNE trending faults, Galong Temple fracture on NW direction Galong Jiali fault passes through the tunnel entrance hole. the north of Tramo-Manyon fracture be located on the tunnel west side of the $300 \mathrm{~m}$, the size of fault zone is relatively large, respectively as the Holocene and late Pleistocene active fault, the landform control effect is very obvious. Has occurrence of 7.0 7.5 earthquake tectonic conditions (the south of Zhamo-Manyon fracture has the structural condition for magnitude 8.0 or greater earthquakes) in the near field region. Tunnel rock was broken ${ }^{7}$.

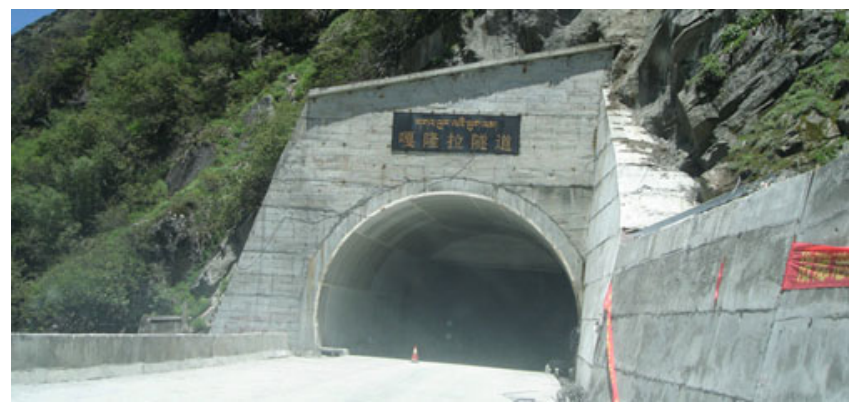

Figure 2. The photo of Galongla tunnel

\section{Computational model}

Due to the Galong temple fracture of Jiali fault zone near the entrance to the cave, the entrance of cave is more vulnerable to earthquake damage, so select the $305 \mathrm{~m}$ position along the axial distance from the hole, intercepted a cross-sectional for analysis, where the tunnel buried deep $152 \mathrm{~m}$. The computational model is shown in Figure 3. The finite element region range is

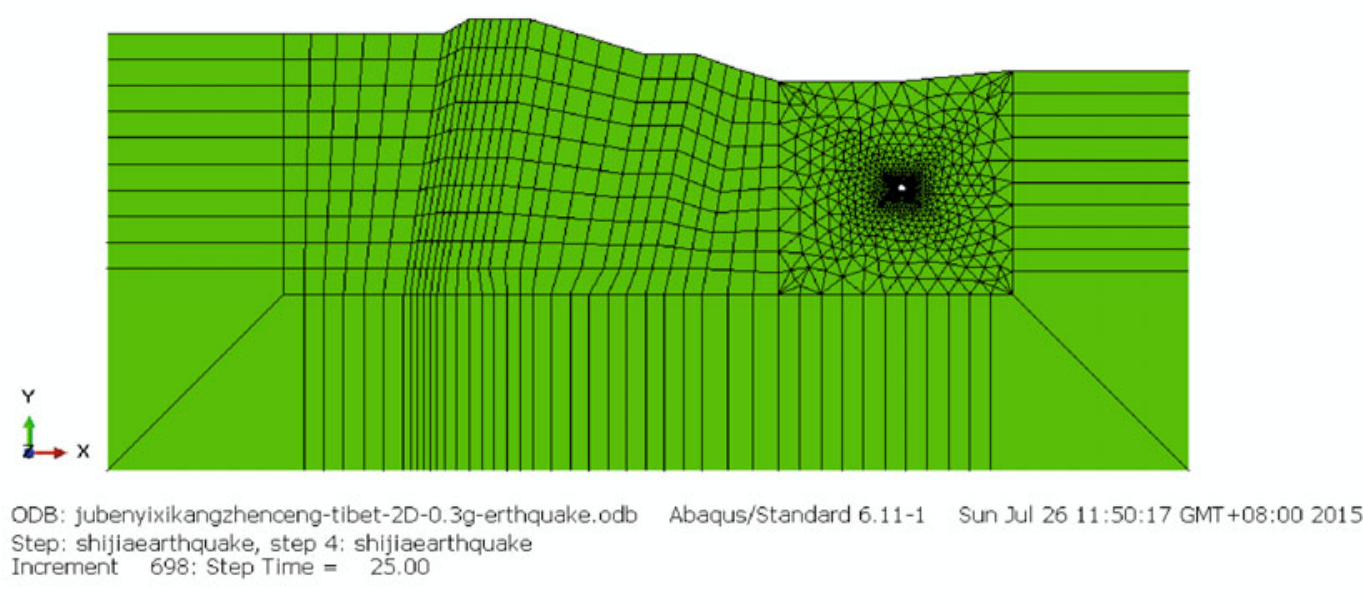

Figure 3. Integral discrete mesh (finite element and infinite element) 
$1030 \mathrm{~m} \times 357 \mathrm{~m}$ (width $\times$ height, average high value) Infinite element dynamic artificial boundary was used in the bottom edge and two side edges ${ }^{8}$.

The finite element software ABAQUS is used to calculate, the surrounding rock and lining adopts Mohr-Coulomb plastic model, the initial lining thickness is $20 \mathrm{~cm}$, the two lining thickness is $50 \mathrm{~cm}$. In the initial lining and surrounding rock, a layer of polystyrene was set up, and the polystyrene thickness was $20 \mathrm{~cm}$, the tunnel lining and seismic layer element mesh are shown in Figure 4. The experimental stress and strain curves were used to establish the constitutive model of polystyrene, stress-strain curves are shown in Figure 1.

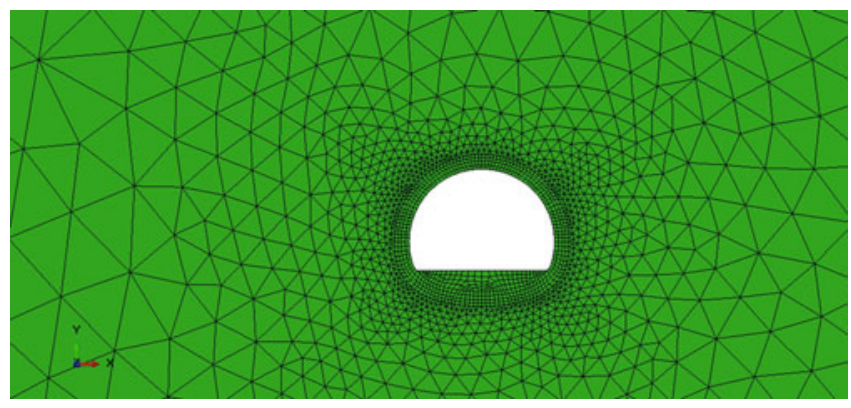

Figure 4. Finite element meshes near the tunnel entrance

\section{Seismic response time history analysis}

Galongla tunnel has structural conditions for more than 8 magnitude earthquake. According to 50 years, with $10 \%$ exceeding probability, the peak acceleration of ground motion is $0.3 \mathrm{~g}^{9}$. According to seismic safety assessment report, enter Kobe earthquake wave ${ }^{\mathbf{1 0}}$, Kobe seismic wave as shown in Figure 5, the duration of seismic wave is 25 seconds. Below the surface within $50 \mathrm{~m}$ in Galongla tunnel portal section, rock is mainly stone, gravel and weathered schist, surrounding rock structure is relatively loose, and stability is poor, below the surface $50 \mathrm{~m}$, rock is mainly weak weathered granite, and the comprehensive evaluation of the surrounding rock is five grades. According to the geological prospecting data, the mechanical parameters of surrounding rock are shown in Table $2^{\mathbf{1 1}}$.

A situation of extreme danger in an earthquake, that is, the shear wave is simulated by input $\mathrm{x}$ direction earthquake acceleration time history at the bottom of finite area. In addition, because of the influence of material damping on the seismic results is very small, the calculation will not be considered.

\section{Calculation scheme}

In the seismic analysis and design, the author firstly concerns the effect of applying the seismic layer, and the second is concerned with the difference of seismic performance of different materials, to this end, this paper has carried on the analysis of 2 kinds of schemes for the no earthquake resistant layer and seismic resistant layer.

\section{Calculation results and analysis}

By comparing the two acceleration responses in Figure 6 and Figure 7, it was found that the acceleration response of the tunnel was enlarged after the base isolation layer.

By contrasting the above two main stress reaction processes illustrated in Figure 8 and Figure 9, we see that the seismic effect of the polyethylene seismic layer is excellent, the stress is reduced by $90 \%$, and the stress is only the original $1 / 10$.

The comparison between the above two main stress reaction processes demonstrated in Figure 10 and Figure 11 shows that the three principal stress SP3 of the two lining arch bottom point on axis with polystyrene resistant layer was reduced by $80 \%$, stress is only the original $20 \%$.

By contrasting the main stress reaction process diagrams shown in Figure 12 and Figure 13, we see that the equivalent strain value of the inner lining with polystyrene seismic layer is close to zero, the equivalent strain value of the arch foot is $3.076 \mathrm{e}-4$, the equivalent strain value

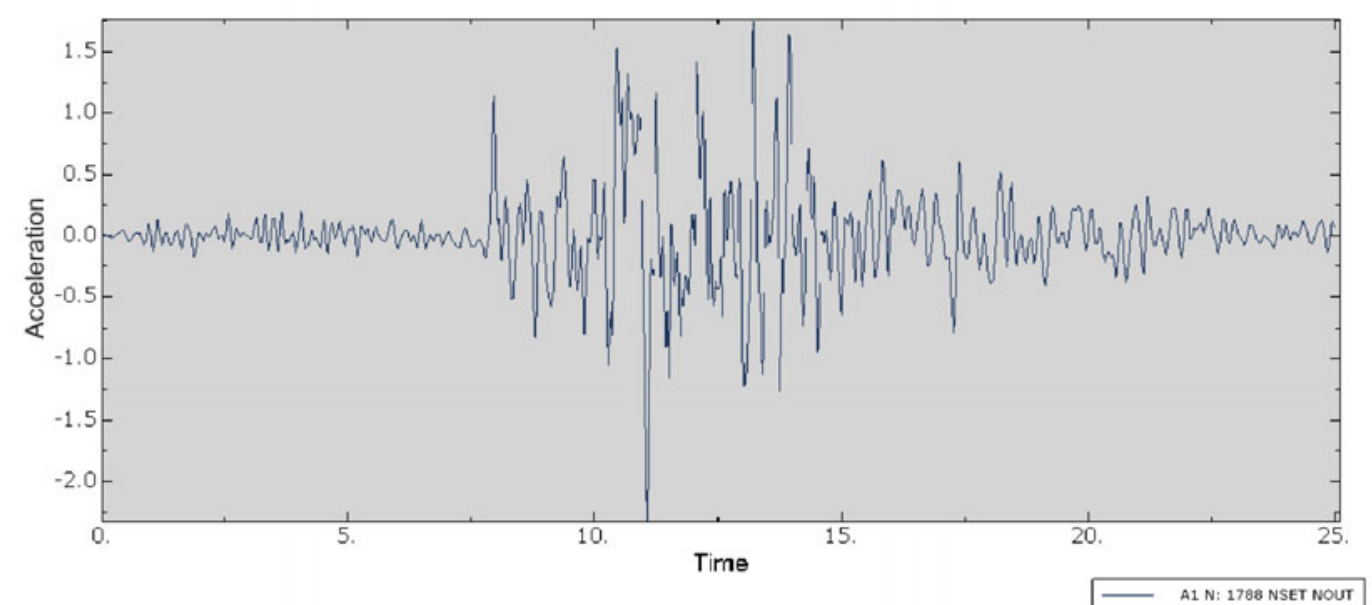

Figure 5. Acceleration time-history curve of Kobe earthquake north-south component

Table 2. Material parameters of surrounding rock and tunnel lining

\begin{tabular}{|l|c|c|c|c|c|c|}
\hline Material & $\begin{array}{c}\text { Elastic modulus } \\
{[\mathrm{GPa}]}\end{array}$ & Poisson ratio & Cohesion [GPa] & Friction angle $\left[{ }^{\circ}\right]$ & Dilatancy angle $\left[{ }^{\circ}\right]$ & $\begin{array}{c}\text { Density } \\
\left.\left[\mathrm{kg} \cdot \mathrm{m}^{-3}\right)\right]\end{array}$ \\
\hline Surrounding rock & 6.0 & 0.30 & 0.20 & 39.0 & 39.0 & 58.7 \\
\hline $\begin{array}{l}\text { Primary lining } \\
\text { concrete }\end{array}$ & 25.2 & 0.20 & 0.96 & 51.0 & 51.0 & 2500 \\
\hline Two lining concrete & 30.0 & 0.20 & 1.43 & 58.7 & 58.7 & 2500 \\
\hline
\end{tabular}




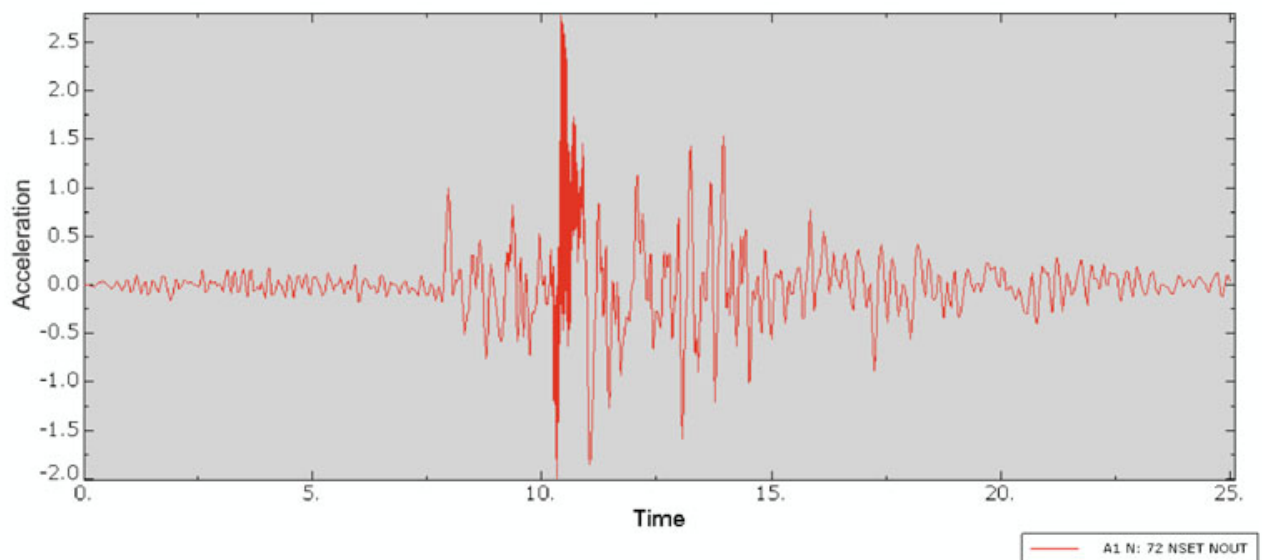

Figure 6. The acceleration response history of the vault inner point by $0.3 \mathrm{~g}$ acceleration input

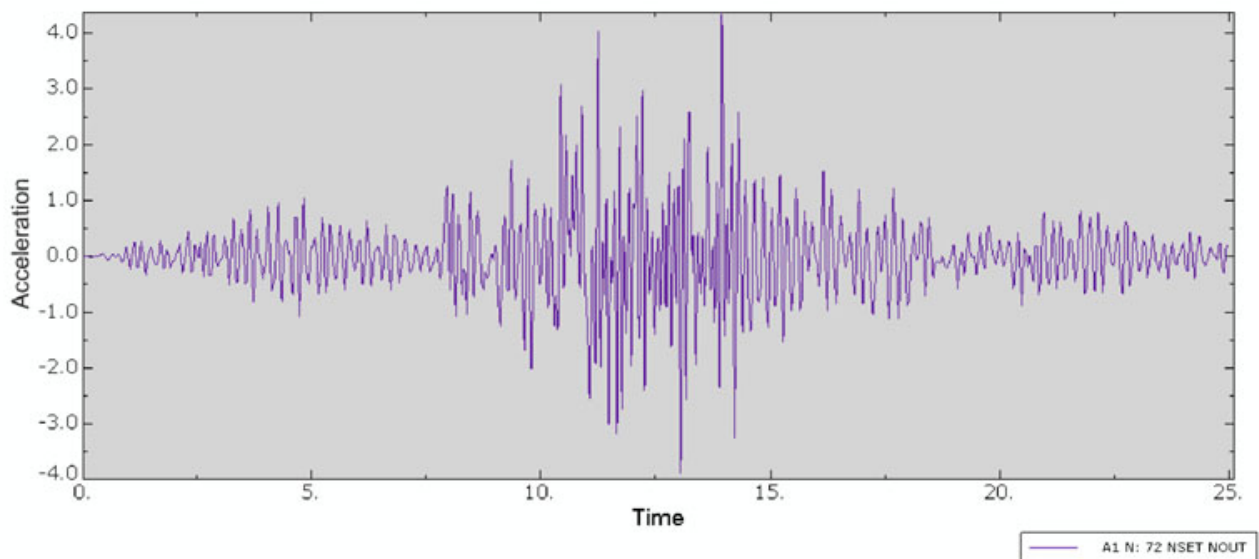

Figure 7. The acceleration response history of the vault inner point with polystyrene resistant layer by $0.3 \mathrm{~g}$ acceleration input

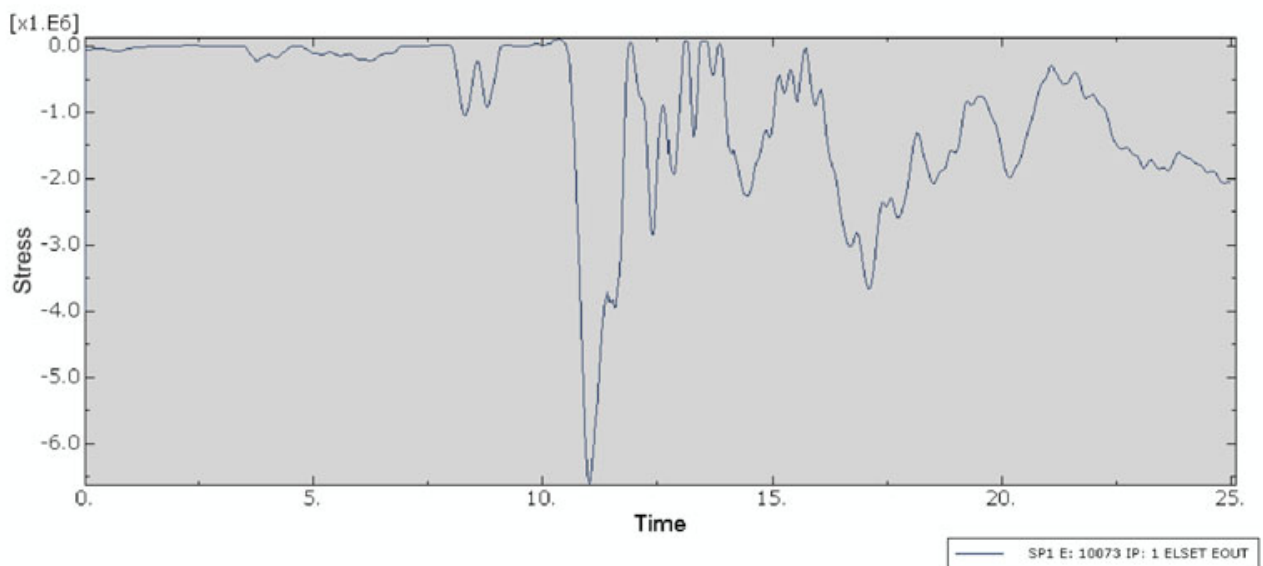

Figure 8. The First principal stress SP1 response history of the vault inner point

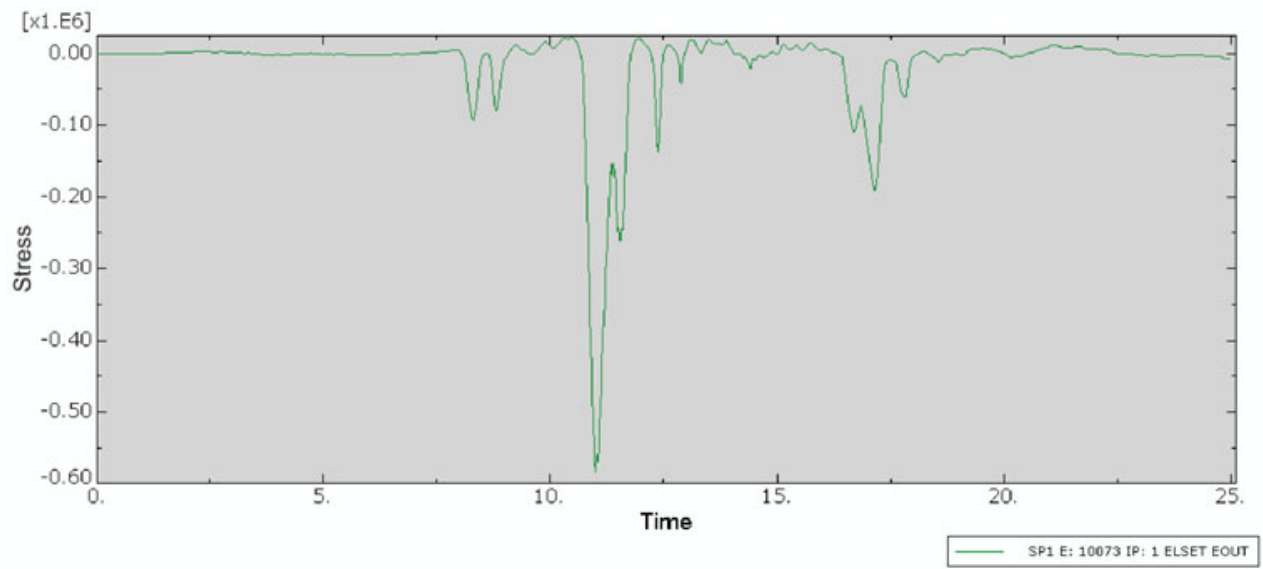

Figure 9. The first principal stress SP1 response history of the vault inner point with polystyrene resistant layer 


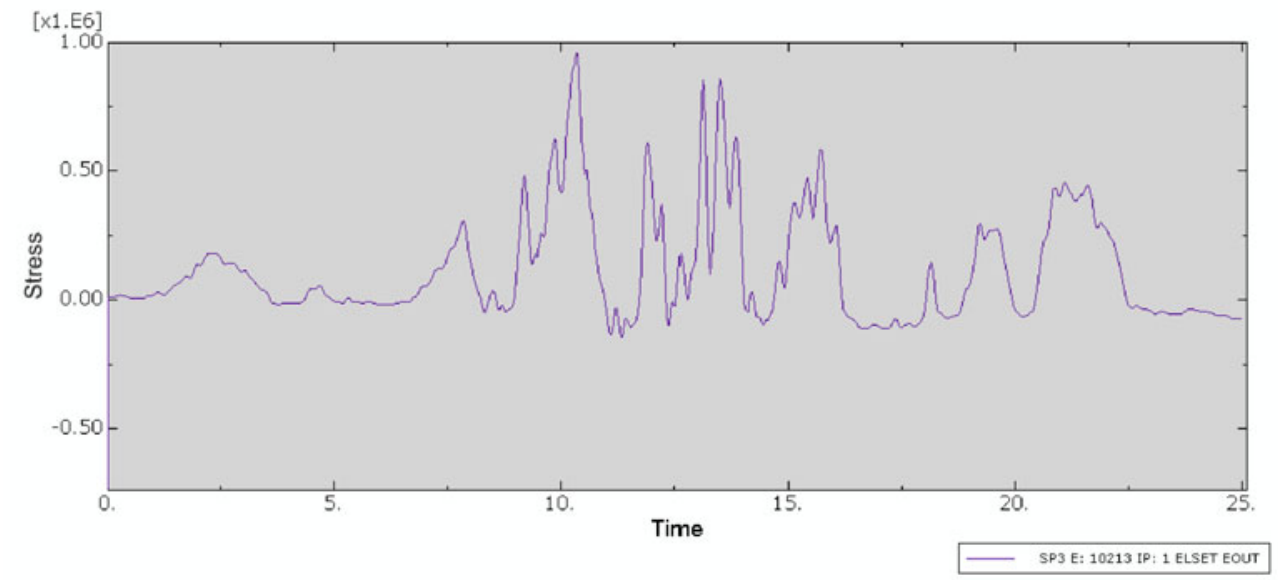

Figure 10. The three principal stress SP3 response history of the two lining arch bottom point on axis

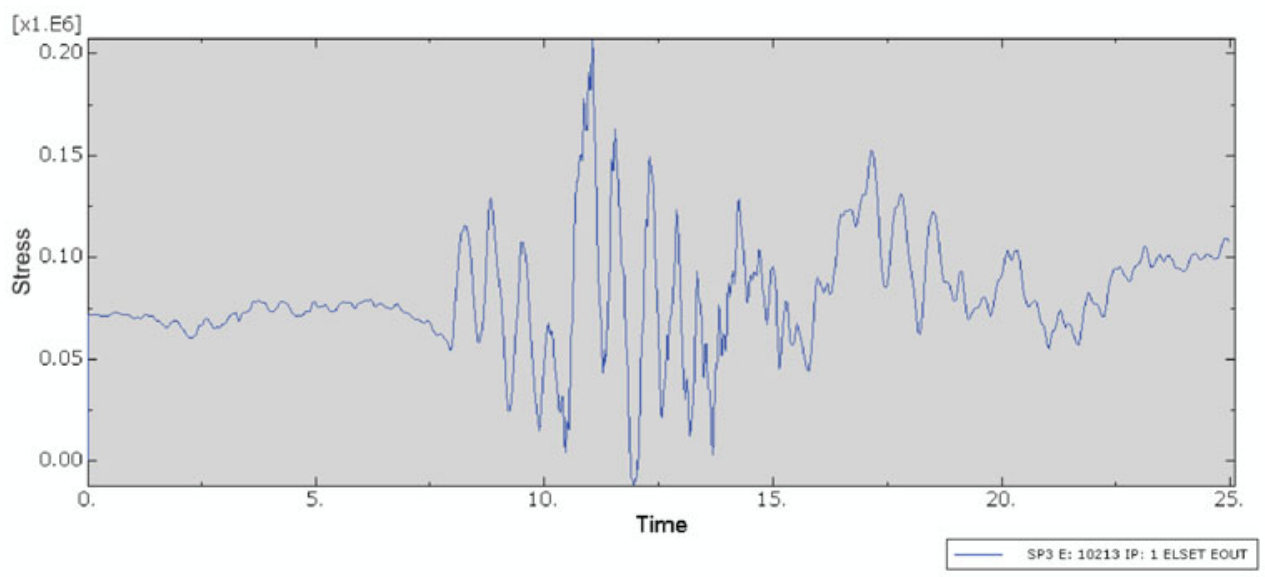

Figure 11. The three principal stress SP3 response history of the two lining arch bottom point on axis with polystyrene resistant layer

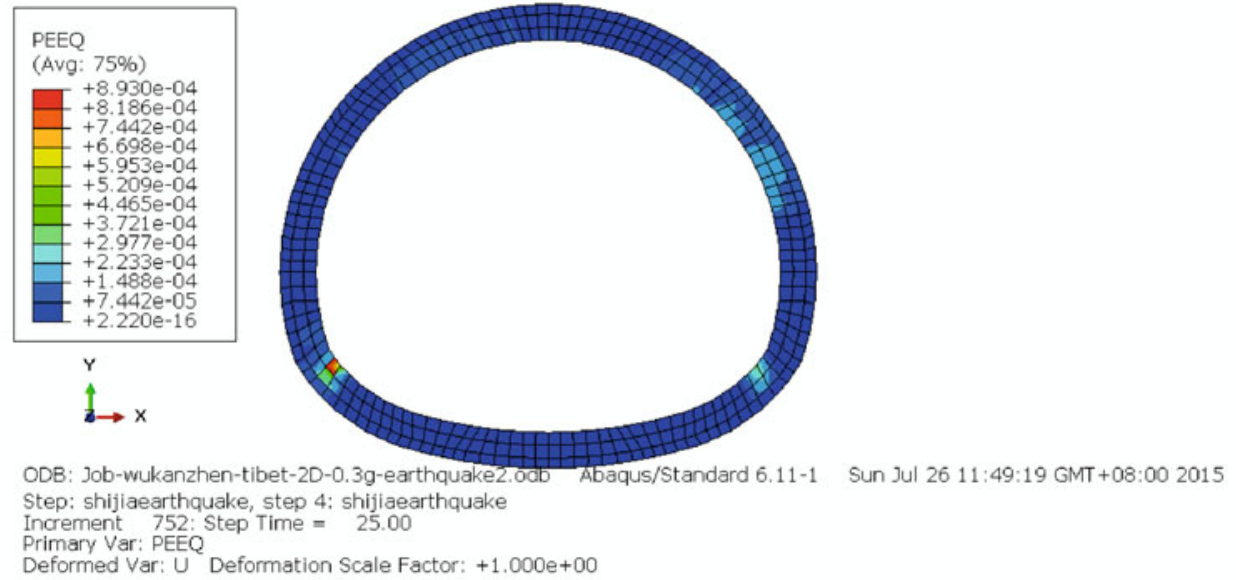

Figure 12. The equivalent plastic strain contour of the tunnel inside lining and outer lining at the end of the earthquake
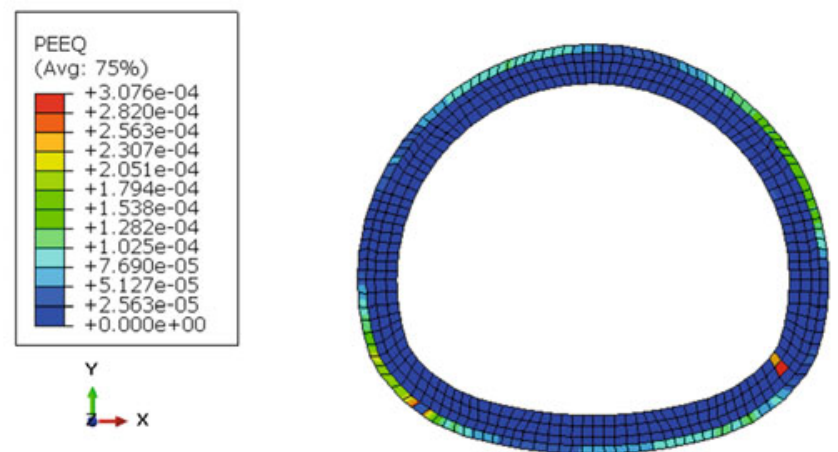

ODB: jubenyixikangzhenceng-tibet-2D-0.3g-erthquake.odb Abaqus/Standard 6.11-1 Sun Jul 26 11:50:17 GMT+08:00 2015 Step: shijiaearthquake, step 4: shijiaearthquake Increment 698: Step Time $=25.00$

Deformed Var: $U$ Deformation Scale Factor: $+1.000 e+00$

Figure 13. The equivalent plastic strain contour of the tunnel inside lining and outer lining with polystyrene resistant layer at the end of the earthquake 
of the non seismic resistant layer is $8.930 \mathrm{e}-4$, and the equivalent effect is reduced by $66 \%$.

From Table 3, after adding the seismic layer, the acceleration value of the tunnel lining was obviously enlarged, that was mainly due to the boundary effect ${ }^{12}$. In the maximum principal stress, the difference between the seismic layer and the no seismic layer is obvious, the maximum principal stress of the vault was significantly decreased; After setting the earthquake resistant layer, the minimum principal stress value of the arch is also significantly reduced, arch bottom are tensile stress; setting earthquake layer, the equivalent plastic strain value of the inner lining is almost zero, only the outer lining has some residual plastic effect, at the end of the earthquake, the equivalent plastic strain value of the arch foot is obviously decreased. It can be seen that the seismic layer has a significant effect on the earthquake.
2. Xu, H. \& Li, T.B. (2011). Seismic dynamic response and damping effect analysis of different buffer layers on tunnels. China Civil Eng. J. 44, 201-208.

3. Geng, P., Tang, J.L., Quan, Q.L., He, C. \& Yan, Q.X. (2013). Shaking table test for tunnel with shock absorption layer though fault zone. J. Central South Univ. (Sci. Technol.) 44(6), 2520-2526.

4. Wang, M.N. \& Cui, G.Y. (2011). Establishment of tunnel damping model and research on damping effect with model test in highly seismic area. Rock Soil Mech. 31(6), 1884-1890. DOI: 10.3969/j.issn.1000-7598.2010.06.035.

5. Chen L., Wang Y.L., Wen D.L. \& Wu C. (2013). Longitudinal seismic response and effect of aseismatic joint of tunnel entrance in fault zone. Transport. Sci. Technol. 260(5), 86-90. DOI: $10.3963 /$ j.issn.1671-7570.2013.05.030.

6. Li, L.J., Ma, C.X. \& Ji, H.W. (2010). A study on the constitutive model and parameter identification of polystyrene plastic foam, Thirteenth National Conference on Packaging Engineering.

Table 3. The values of seismic response for two schemes

\begin{tabular}{|l|c|c|c|c|}
\hline & $\begin{array}{c}\text { Maximum horizontal } \\
\left.\text { acceleration at vault [m/s } \mathrm{s}^{2}\right]\end{array}$ & $\begin{array}{c}\text { Maximum principal stress } \\
\left.\text { at vault [MP } \mathrm{M}_{\mathrm{a}}\right]\end{array}$ & $\begin{array}{c}\text { Minimum principal stress at } \\
\text { arch bottom [MP } \mathrm{a}\end{array}$ & $\begin{array}{c}\text { Equivalent plastic strain } \\
\text { value at arch foot }\end{array}$ \\
\hline $\begin{array}{l}\text { No seismic } \\
\text { layer }\end{array}$ & 2.75 & -6.60 & 0.90 & $8.930 \mathrm{e}-4$ \\
\hline Polystyrene & 4.50 & -0.58 & 0.20 & $3.076 \mathrm{e}-4$ \\
\hline
\end{tabular}

\section{CONCLUSIONS}

Relying on the Tibet Zamo highway Galongla tunnel, we carried out the numerical simulation test of the effect of the polystyrene foam isolation layer in the tunnel entrance. Numerical results show that under the action of shear seismic wave, the maximum principal stress and the minimum principal stress of the two lining element. The application of the foam isolation layer is greatly reduced, plastic zone area decreased significantly. It is proved that the isolation layer of polystyrene foam has good isolation effect. The research results have good reference value for the seismic design of tunnel and underground engineering in the west of China.

In addition, from the plastic zone, there is a large plastic strain value in the tunnel hole without seismic layer, this means that the lining may be destroyed; after setting the seismic layer, the plastic zone is only in the foot part of the arch. Thus, the dynamic response of the lining structure can not be changed from the root, but through the isolation buffer of the seismic layer, can improve the stress state of lining. The tunnel lining is not destroyed in the earthquake with the protection of seismic layer.

By the research of this paper, in high seismic intensity area, the polystyrene foam Seismic layer is set up, cut off the binding force of the surrounding strata to the tunnel, reducing and changing the intensity and mode of the effect for earthquake to the structure, and the good energy absorption properties of the porous medium, it can well absorb the strain and strain energy of the surrounding rock to tunnel structure, so as to effectively reduce the damage and protect the lining.

\section{LITERATURE CITED}

1. Jiang, H., Jiang, S.P., Wang, X.W. \& Lin, Y. (2009). Study on transverse seismic response of highway tunnel in fault region. Tunnel Constr. 29(1), 14-18.
7. Huang, S., Chen, W.Z., Yang, J.P., Guo, X.H. \& Qiao, C.J. (2009). Research on earthquake-induced dynamic responses and a seismic measure for underground engineering. Chinese J. Rock Mech. Eng. 28(3), 483-490. DOI: 10.3321/j.issn:10006915.2009.03.006.

8. Zhao, W.S., Chen, W.Z., Zheng, P.Q. \& Yu, J.X. (2013). Choice and implementation of seismic wave input method in numerical calculation for underground engineering. Chinese $J$. Rock Mech. Eng. 32(8), 1579-1587.

9. Huang, S. (2010). Research on failure mechanism and a seismic measure for underground engineering under high intensity earthquake, Wuhan Institute of Rock and Soil Mechanics, Chinese Academy of Sciences, P.R.China, May, 2010.5.

10. Hiroomi, I. et al. (1996). Damage to Daikai subway station. Soils and Foundations, Special Issue, Jan, 283-300.

11. Zhao, W.S., Chen, W.Z., Tan, X.J. \& Huang, S. (2013). High-performance foam concrete for seismic-isolation materials of tunnels. Chinese J. Geotech. Eng. 35(8), 1544-1552.

12. Zheng, Y.L., Yang, L.D. \& Li, W.Y. et al. (2005). Earthquake resistance of underground structures. Shanghai: Tongji University Press. 